\title{
Lytic Lesion in the Distal Phalanx of the Hand
}

\author{
Khodamorad Jamshidi ${ }^{1}$; Farid Najd Mazhar ${ }^{1, *}$; Davod Jafari ${ }^{1}$ \\ ${ }^{1}$ Bone and Joint Reconstruction Research Center, Shafa Orthopedic Hospital, Iran University of Medical Sciences, Tehran, IR Iran \\ ${ }^{*}$ Corresponding author: Farid Najd Mazhar, Shafa Orthopedic Hospital, Iran University of Medical Sciences, Tehran, Iran. Tel: +98-2133542022, Fax: +98-2133542020, E-mail: fnajd- \\ mazhar@yahoo.com
}

Received: June 20, 2014; Revised: December 16, 2014; Accepted: December 25, 2014

\begin{abstract}
Background: Both primary and secondary tumors can develop in distal phalanx of the hand presenting as lytic lesions. The presence of a lytic lesion in the distal phalanx has been a dilemma making the differential diagnoses, prognosis, and treatment of these lesions challenging.

Objectives: This study was designed to evaluate the patients who were presented with a lytic lesion in their distal phalangeal bone of the hand.

Patients and Methods: In this retrospective study, we reviewed the final diagnosis, clinical presentation, treatment, and outcomes of the lytic lesions in distal phalangeal bones of the hand in 14 patients who were referred to our hospital from 2008 to 2013.

Results: The mean age of our patients was $36.14 \pm 15.8$ years. Thumb and middle finger were the most common involved digits (four cases of each) followed by the index finger (three patients). Enchondroma was the most common final diagnosis (five patients) followed by giant cell tumor and glomus tumor (two cases of each). Painless mass was the chief complaint of most patients with enchondroma, whereas pain and swelling were the chief compliant of others. Enchonromas were located in the proximal part of the distal phalanx and other lytic lesions were seen in the distal part.

Conclusions: Because of the diverse diagnosis for the lytic lesions in the distal phalanx of the hand, a complete tumor work-up should be performed to evaluate the condition properly, especially in distally located lesions.
\end{abstract}

Keywords: Distal; Phalanx; Tumor

\section{Background}

Although osteolytic lesions of the distal digital phalanx are rare, they present a wide spectrum of differential diagnoses. Distal phalanx of the hand can be affected by primary or secondary tumors and inflammatory process. Enchondroma is the most common benign tumor of phalangeal bones occurring most commonly in the proximal phalanx, middle phalanx, and the metacarpals, consecutively. Its occurrence in distal phalanx is rare (1). Metastases of malignant tumors of lung, breast, kidney, and prostate origin can involve the phalangeal bones, specially the distal one (2). Giant cell reparative granuloma, giant cell tumor, epidermoid inclusion cyst, glomus tumor, brown tumor, and Ewing sarcoma have been reported as a lytic lesion in distal phalanx (3-5). We could not find any study in the literature that solely concentrated on the tumors of the distal phalanx.

\section{Objectives}

This case series study aimed to describe the final diagnoses of lytic lesions in distal phalangeal bones of the hand in 14 patients as well as the methods of surgery and their outcomes.

\section{Patients and Methods}

Our institutional review board approved the study protocol. In this retrospective study, we recruited patients who were referred to our hospital (Shafa Orthopedic Hospital) due to the lytic lesions of the distal phalanx from 2008 through 2013. We reviewed the medical records, results of imaging modalities, and histopathologic examination reports. Data on basic characteristics, chief complaint, the involved finger, clinical presentation, the final diagnosis, and the applied treatment were extracted. The surgeries had been performed under general anesthesia, with application of a tourniquet to the proximal part of the arm. In all cases, the distal phalanx was exposed with medial or lateral approaches. Curettage was done for enchondroma, giant cell tumor, giant cell reparative granuloma, and intraosseous glomus tumor and the defect was filled with bone graft. For Ewing sarcoma sarcoma of distal thumb, surgery and entailed excision of distal phalanx and biopsy tract were performed two weeks after neoadjuvant chemotherapy. In this instance, reconstruction was done with a fresh-frozen allograft counterpart (obtained from our hospital bone bank) that was fused to the first phalanx (Table 1). 
Jamshidi Ket al.

\begin{tabular}{|c|c|c|c|c|c|c|c|}
\hline $\begin{array}{l}\text { Number of } \\
\text { Patients }\end{array}$ & Gender & Age, $y$ & $\begin{array}{l}\text { Involved } \\
\text { Finger }\end{array}$ & Diagnosis & Treatment & Follow-up, mo & $\begin{array}{c}\text { Chief } \\
\text { Complaint }\end{array}$ \\
\hline 01 & Female & 32 & Lt Index & Enchondroma & Curettage and Bone graft & 58 & $\begin{array}{l}\text { Pain and } \\
\text { Swelling }\end{array}$ \\
\hline 02 & Male & 25 & Lt Thumb & GCRG & Curettage and Bone graft & 46 & $\begin{array}{l}\text { Pain and } \\
\text { Swelling }\end{array}$ \\
\hline 03 & Male & 32 & Rt Middle & Enchondroma & Curettage and Bone graft & 26 & Swelling \\
\hline 04 & Female & 29 & Rt Index & Enchondroma & Curettage and Bone graft & 48 & Swelling \\
\hline 05 & Female & 23 & Lt Ring & Glomus tumor & Excision and Curettage & 18 & Pain \\
\hline 06 & Male & 75 & Lt Thumb & SCC of lung & Amputation & $\begin{array}{l}\text { Deceased after } \\
11 \text { months }\end{array}$ & $\begin{array}{l}\text { Pain and } \\
\text { Swelling }\end{array}$ \\
\hline $\mathbf{0 7}$ & Female & 21 & Rt Middle & EIC & Curettage & 60 & Swelling \\
\hline 08 & Female & 44 & Rt Thumb & $\begin{array}{l}\text { Hyperparathy- } \\
\text { roidism }\end{array}$ & Parathyroidectomy & 43 & Swelling \\
\hline 09 & Female & 42 & Lt Middle & Enchondroma & Curettage and Bone graft & 44 & Swelling \\
\hline 10 & Male & 36 & Rt Index & GCT & Curettage and Bone graft & 20 & $\begin{array}{l}\text { Pain and } \\
\text { Swelling }\end{array}$ \\
\hline 11 & Male & 22 & Lt Thumb & Ewing sarcoma & $\begin{array}{l}\text { Phalanx resection and re- } \\
\text { construction with allograft } \\
\text { and IP joint fusion }\end{array}$ & 12 & Pain \\
\hline 12 & Female & 32 & Lt Little & Enchondroma & Curettage and Bone graft & 22 & $\begin{array}{l}\text { Pain and } \\
\text { Swelling }\end{array}$ \\
\hline 13 & Female & 64 & Lt Ring & GCT & Curettage and Bone graft & 38 & $\begin{array}{l}\text { Pain and } \\
\text { Swelling }\end{array}$ \\
\hline 14 & Female & 29 & Lt Middle & Glomus tumor & Excision and Curettage & 42 & $\begin{array}{l}\text { Pain and } \\
\text { Swelling }\end{array}$ \\
\hline
\end{tabular}

\section{Results}

A total of 14 patients (nine females) with distal phalanx lytic lesion were studied. The mean age of our patients was $36.14 \pm 15.83$ years (range, 21-75 years). Right and left side fingers were involved in five and nine patients consecutively. The most common involved digits were thumb (four cases), middle finger (four cases), and index finger (three cases), consecutively. The most frequent diagnosis were consecutively enchondroma (five cases), giant cell tumor (two cases), and glomus tumor (two cases).

The presence of a swelling and painless mass were the chief complaints of most patients with enchondroma (two of our cases had pain after minor trauma). Pain and swelling were the chief complaints of patients with other tumors (Table 1 ).

The final diagnosis of all the lesions located in the proximal part of the distal phalanx was enchondroma (Figure 1); lesions of all other tumor types were located in the distal part of distal phalanx (Figures 2 - 6). Radiologic studies of the metastatic carcinoma and giant cell tumors showed more aggressive behavior and involvement of surrounding soft tissue (Figures 3 and 5). One of our patients (patient No. 6) deceased after 11 months. For the rest of our cases, the mean follow up was 36.69 months (range, 12-58 months) and none of them had recurrence during the follow-up period.

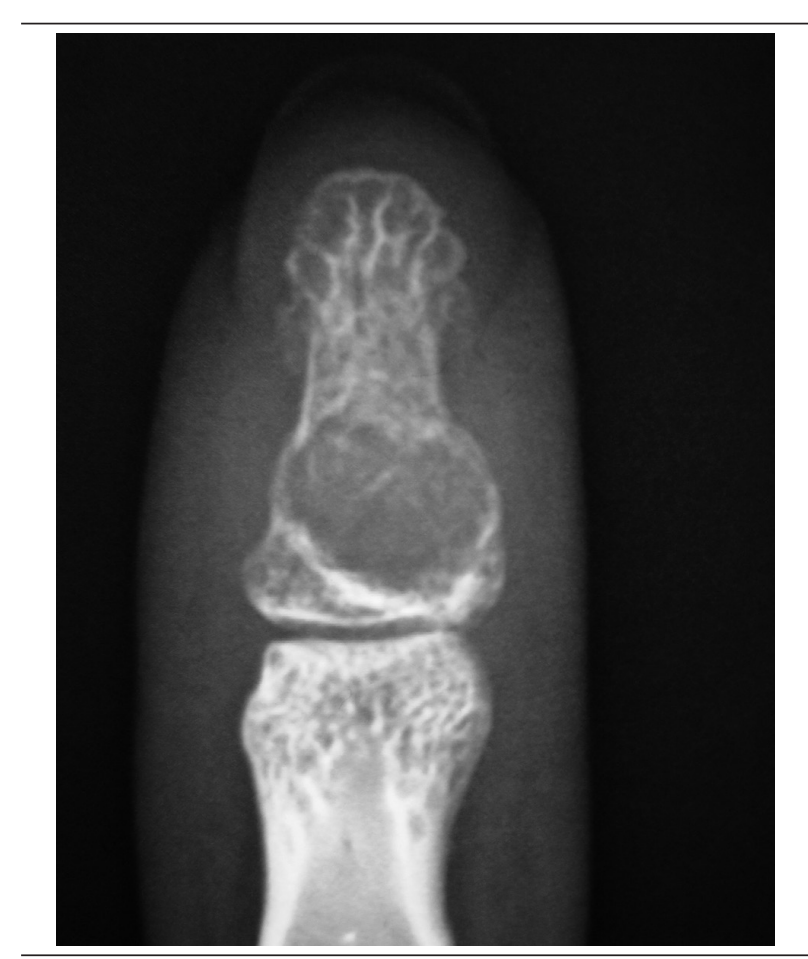

Figure 1. Anteroposterior Radiographic View of the Distal Phalanx Showing Proximally Based Lytic Lesion Expanding the Cortex (Enchondroma, Patient 1) 


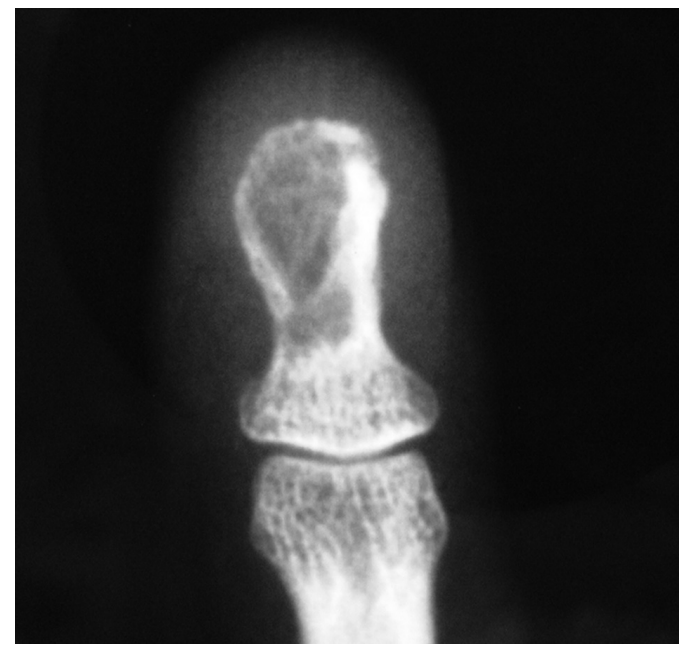

Figure 2. Anteroposterior Radiographic View of the Distal Phalanx Showing Distally Based Well Defined Lytic Lesion (Glomus Tumor, Patient 5)

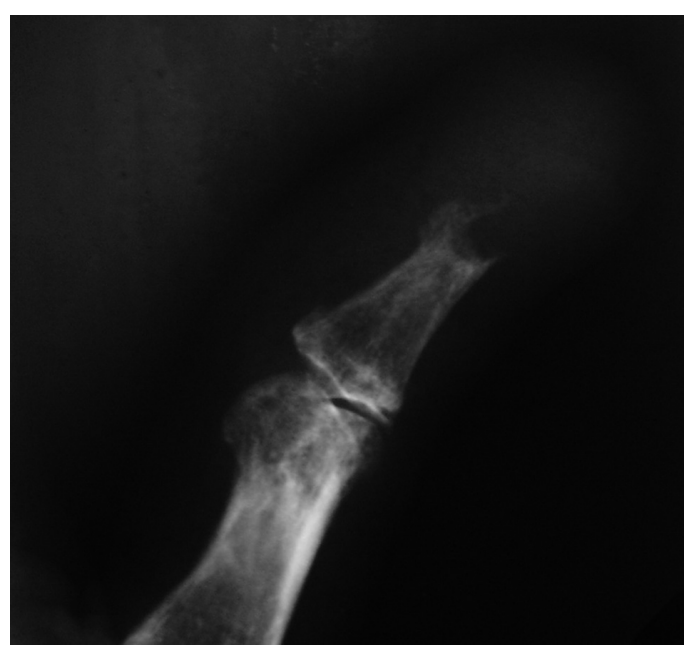

Figure 3. Anteroposterior Radiographic View of the Distal Phalanx of the Thumb Showing Distally Based Ill-Defined Lytic Lesion and Soft-Tissue Component (Metastatic Squamous Cell Carcinoma, Patient 6)

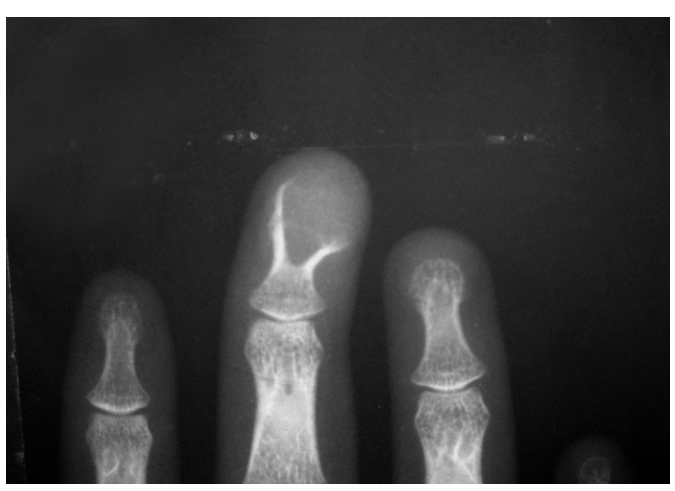

Figure 4. Anteroposterior Radiographic View of the Distal Phalanx of the Thumb Showing Distally Located Well-Defined Lytic Lesion and Soft Tissue Component (Epidermoid Inclusion Cyst, Patient 7)

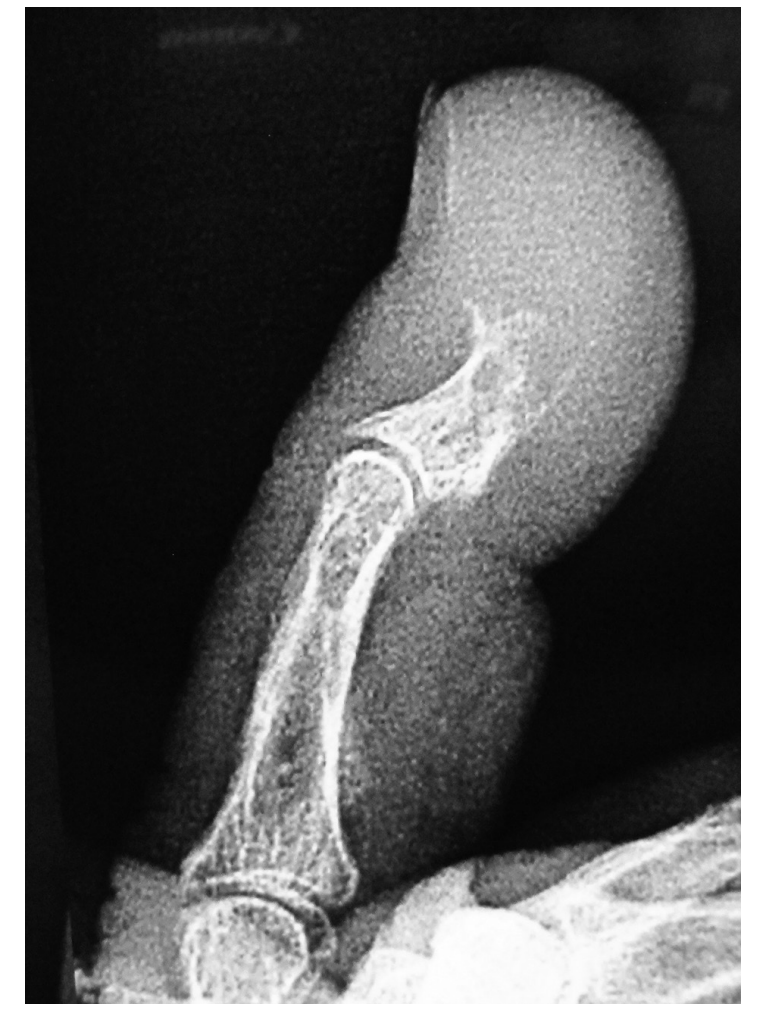

Figure 5. Lateral Radiographic View of the Distal Phalanx of the Ring Finger Showing Distally Located Lytic Lesion and Soft Tissue Component. (Giant Cell Tumor, Patient 13)

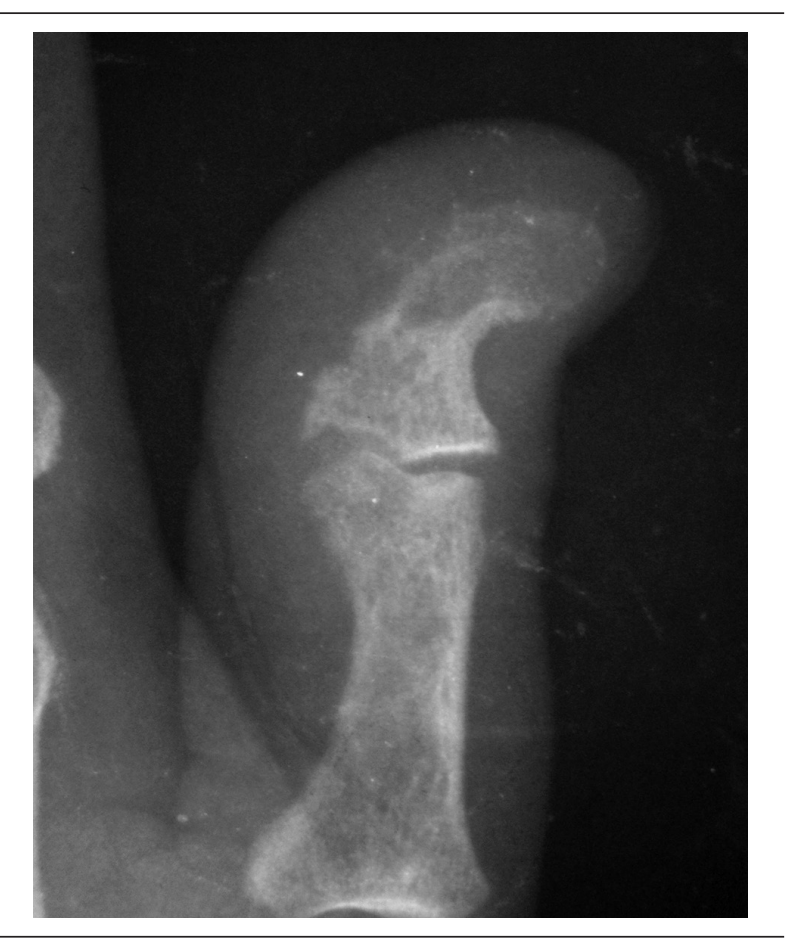

Figure 6. Oblique Radiographic View of the Distal Phalanx of the Thumb Showed Absorption of the Tuft (Hyperparathyroidism, Patient 8) 


\section{Discussion}

Although enchondroma is the most frequent bone tumor in the small bones of the hand, it rarely develops in the distal phalanx. Noble and Lamb reported that 13\% of mono-ostotic and polyostotic enchondromas developed in the distal phalanx (6). Fernandez-Vazquez et al. found that only $12.8 \%$ of hand enchondroma developed in distal phalanx (7). In our series enchondroma was the most common cause of the lytic lesion of the distal phalanx.

Clinically, the majority of the hand tumors are benign and a large number of them develop insidiously without significant pain or tenderness; thus, cosmetic concerns such as swelling may be the patient's only presenting complaint (8). The others such as glomus tumor, infection, and metastatic and primary malignant tumor may present with pain.

Glomus tumors are painful subcutaneous nodules associated with intense pain. In distal phalanx, the triad of the intense pain, local tenderness, and cold intolerance can be attributed to the glomus tumor (9). Painful lesions with a presentation mimicking an infection can be actually caused by Ewing sarcoma of the distal phalanx, which is extremely rare (3).

Metastatic tumors in the osseous tissues of the hand are rare and most commonly present with pain, swelling, and nail deformity. Metastases to the bones of the hand may occur in carcinoma of the lung (40\%), breast (16\%), kidney (6\%), and prostate (3\%), most of which occur in the distal phalanges $(2,10)$. Chondrosarcoma is the most common non-metastatic malignant bony tumor of the hand and is usually seen as secondary chondrosarcoma in previous Ollier's disease. It presents as painful lytic lesion with popcorn calcification in small tubular bones of hand (11).

Recently, Afshar et al. reported a review of published studies on demographic trends, survival rates, and the most common metastatic locations of hand and wrist metastases over the past 27 years. They reported 221 cases; the distal phalanx was the most frequently involved bone, and the thumb was the most frequently involved digit (12).

Swelling and a painless mass without nail deformity were the chief complaints of our patients with the diagnosis of enchondroma. Two of our patients with this tumor had pain after minor trauma. All of our patients with the non-enchondroma diagnoses presented with a painful swelling of the distal phalanx. Radiologically, periosteal reaction was not seen in any of our cases reported here and considering the location of the lesions, we categorized them in two groups:

Group one included the proximally located lytic lesions and the second group included distally located lytic lesions. All of the enchondromas were in group one, ie, the proximally located lesions, two of which had minor cortical expansion. All of the remaining lesions were in the second group.
Shimizu K. et al. reported five cases of enchondroma of distal phalanx. Three of their patients, who had developed fractures, were treated with curettage and bone grafting through a volar longitudinal approach. The authors reported that the palmar incision in the pulp of the finger had no complications (13). Although traditionally the universal approach in the hand surgery is Brunner type zig-zag incision, we found that by the selection of medial or lateral subungual approach and elevation the volar skin flap, including neurovascular bundle, the surgeon would be able to excise soft tissue component of the tumor and expose the entire distal phalanx more easily.

The result of the present study indicates that the bony lytic lesions of distal phalanxes of the hand are most commonly benign and are due to enchondroma. Although malignant bony tumors of the hand are rare, this study shows that Ewing sarcoma or squamous cell carcinoma can also present themselves as lytic lesions in distal phalanx (Table 1).

Interesting aspect of the present study is the diversity of the final diagnoses of distal phalangeal lytic lesions. Most of the lesions were benign and enchondroma was the most common type. On the other hand, very rare tumors in the hand such as Ewing sarcoma represented themselves as a lytic lesion in the distal phalanx. Given the diversity of final diagnoses, the study indicates that any lytic lesion in distal phalanx of the hand, especially in its distal part, should undergo complete tumor work-up.

\section{Authors' Contributions}

Study concept, design, drafting the manuscript, and critical revision of the manuscript: Khodamorad Jamshidi, Farid Najd Mazhar, and Davod Jafari. Analysis and interpretation of data: Khodamorad Jamshidi and Farid Najd Mazhar. Study supervision: Khodamorad Jamshidi.

\section{References}

1. Dorfman HD, Czerniak B. Benign cartilage lesions. Dorfman HD, Czerniak B editors. St Louis: Mosby; 1998.

2. Martin KA, Dove AF. Metastatic carcinoma of the hand. Hand. 1983;15(3):343-6.

3. Jamshidi K, Najd Mazhar F, Moghimi J. Ewing sarcoma of the distal part of the thumb: allograft reconstruction to preserve function. J Bone Joint Surg. 2013;3:1-6.

4. Merkow RL, Bansal M, Inglis AE. Giant cell reparative granuloma in the hand: report of three cases and review of the literature. $J$ Hand Surg Am. 1985;10 (5):733-9.

5. Takase K. Intraosseous glomus tumour in the distal phalanx of the index finger. J Hand Surg Eur Vol. 2011;36(1):74-6.

6. Noble J, Lamb DW. Enchondromata of bones of the hand. A review of 40 cases. Hand. 1974;6(3):275-84.

7. Fernandez-Vazquez JM, Ayala-Gamboa U, Camacho-Galindo J, Sanchez-Arroyo AC. [Enchondroma of the distal phalanx]. Acta Ortop Mex. 2011;25(6):376-9.

8. Calandruccio JH, Jobe MT. Tumors and tumorous conditions of the hand. 12 th ed. Canale ST, Beaty JS editors. Philadelphia: Elsevier; 2013.

9. Theumann NH, Goettmann S, Le Viet D, Resnick D, Chung CB, Bittoun J, Chevrot A, Drape JL, et al. Recurrent glomus tumors of fingertips: MR imaging evaluation. Radiology. 2002;223(1):143-51. 


\section{Jamshidi Ket al.}

10. Plate AM, Steiner G, Posner MA. Malignant tumors of the hand and wrist. J Am Acad Orthop Surg. 2006;14(12):680-92.

11. Unni KK. Chondroma. Unni KK editor. Philadelphia: JB Lippincott Co.; 1996.

12. Afshar A, Farhadnia P, Khalkhali H. Metastases to the hand and wrist: an analysis of 221 cases. J Hand Surg Am. 2014;39(5): 923-32 e17.

13. Shimizu K, Kotoura Y, Nishijima N, Nakamura T. Enchondroma of the distal phalanx of the hand. J Bone Joint Surg Am. 1997;79(6):898-900. 